\title{
Seismological model parameters for northeastern and its surrounding region of India*
}

\author{
Tauhidur Rahman * \\ Civil Engineering Department, National Institute of Technology, Silchar-788010, Assam, India
}

\begin{abstract}
A point source seismological model is used in this study to model the available strong motion accelerograms recorded by 17 events and to calculate three seismological model parameters, the source, path, and quality factor. Due to the paucity of recorded events, this is the first time these model parameters have been obtained for the northeastern and its surrounding region of India. The quality factors of the horizontal and vertical components of recorded events with corresponding standard deviations are $Q_{\mathrm{H}}(f)=188.55 f^{0.94}, \sigma_{1}$ value $(25,0.025)$ and $Q_{\mathrm{V}}(f)=169.76 f^{0.93}, \sigma_{1}$ value $(20,0.03)$, respectively. The source parameter stress drop values $(\Delta \sigma)$ vary within $124-180$ bars for the subduction region and $80-169$ bars for the active region. The Kappa factors for the horizontal and vertical components of recorded events on the soft rock site are 0.06 and 0.05 , respectively. These seismological model parameters obtained in this study will be useful for future work deriving a ground motion attenuation relation based on a spectral model. Finally, these results are useful for seismic hazard assessment of a region having sparsely recorded events.
\end{abstract}

Key words: spectral model; hazard assessment; model parameter

CLC number: P315.9 Document code: A

\section{Introduction}

Over the past few decades the importance of understanding seismic hazards estimation and focusing research on regions that are susceptible to large earthquakes has become paramount. Seismic source potentials are identified from different faults located in a region. However, it is often difficult to calculate the seismic hazard of a region due to the paucity of recorded events. Recent studies, however, have made attempts to evaluate the seismic hazard parameters for a specific seismically vulnerable region that not only has a scarcity of recorded events but also incomplete ranges of magnitude and epicentral distance. The northeastern and its surrounding region of India is well known for its seismic activity, with 20 large magnitude earthquakes $\left(M_{\mathrm{W}} \geq 8.5\right)$ have occurred during a period of 609 years (1400-2009). Unfortunately, however, because this region locks recording station,

\footnotetext{
* Received 11 March 2012; accepted in revised form 20 June 2012; published 10 August 2012.

* Corresponding author. e-mail: tauhid_srm@yahoo.com

(c) The Seismological Society of China, Institute of Geophysics, China Earthquake Administration, and Springer-Verlag Berlin Heidelberg 2012
}

no seismic records exist. This makes it even more challenging for both seismologists and earthquake engineers to evaluate the seismic hazard for such a region.

On 18 September 2011, a large magnitude $\left(M_{\mathrm{W}} 6.9\right)$ earthquake occurred in the northeastern and surrounding region of India, which destroyed numerous buildings and killed 113 peoples. Recorded seismic data from this recent event is used in this study to calculate the seismological model parameters. A total of 546 three-component strong motion accelerograms from 17 recorded events of magnitude $M_{\mathrm{W}} 4.8-7.3$ are available for this region. Though the northeastern and surrounding region of India has experienced numerous large magnitude earthquakes in the past, there is a lock of the reliable quantifiable information for the earthquake parameters. Information related to the earthquake propagation characteristics such as quality factor, stress drop and site parameters, is not available for the northeastern and surrounding region of India. Moreover, the scarcity of records inhibits development of an attenuation relationship for such a seismically vulnerable region that is valid for all ranges of magnitude and distance. Therefore, researchers face a daunting challenge in attempting to derive the attenuation pattern and calculate the seismic hazard for this type of region. 
The aforementioned issues can be handled by properly selecting of a spectral model for deriving the ground motion attenuation relationship and calibrating for the region-specific source, path and site parameters. The final hazard at the chosen site depends on all three of the above seismological model parameters. In engineering applications, researchers tend to study the regionspecific seismic sources, where ground motion recordings are abundant. It is a common practice to derive the ground motion attenuation relationship based on the available region-specific recorded events. However, in some regions of the world the number of recorded events is insufficient.

Seismological model parameters, specifically the source parameter, quality factor, and site parameter can be used as input parameter for predicting the average expected ground motion amplitude of a region [e.g., Tavakoli and Pezeshk (2005); Boore (2003); Beresnev and Atkinson (2002); Atkinson and Silva (2000); Atkinson and Boore (1998); Toro et al. (1997)]. Atkinson and Silva (2000) used seismological parameters to derive ground motion attenuation relations in California. Toro et al. (1997) used uncertainties in seismological parameters to develop ground motion attenuation relationships. Thus, these seismological model parameters are required for seismologically in synthetic ground motion simulation.

Seismologists, recognizing the stochastic nature of high frequency ground motion, adopted the nonstationary random process model for simulating ground motion time histories and their peak values, by including a physical model to describe the frequency content of the ground motion. Hanks and McGuire (1981) related the root mean square (RMS) acceleration of the SMA's to the $\omega^{-2}$ source spectra of Brune (1970) modified by anelastic and geometric attenuation through the Parseval theorem. Assuming the acceleration time history has a finite duration, is band limited, and of white Gaussian noise, they derived a simple relationship between peak ground acceleration (PGA) and RMS acceleration. Boore (1983, 2003) further extended their results for computing ground motion time histories and response spectra. This model may be universal in format, but the parameters must reflect the local regional properties. Stress drop $(\Delta \sigma)$, quality factor $(Q)$ and site parameter $(\kappa)$ valid for the northeastern and surrounding region of India are calculated using the point source seismological model of Boore (2003) from the available 17 instrument data base for this region. One can confidently say that ground motion depends critically on three model parameters namely the source, the path, and the site. Much of the modeling and simulation of ground motion can be discussed under the headings of source parameters, path parameters, and site parameters. Even though the broad model (Boore, 2003) is universally applicable, it depends on parameters that are applicable to the region under consideration. Thus, the $Q$ factors found for the California region may not be valid for Indian. Similarly, the most important source parameter, the stress drop, may vary depending on the seismotectonic that resulted in the earthquake.

\section{Seismological model}

Seismological models are widely used to predict ground motion attenuation relationship for a region with sparse recorded data. In the northeastern and surrounding region of India, both shallow- and deep-focus earthquakes have occurred. This region is structurally complex, comprised of both active zones and subduction zones. In this study, a point source model is used to calculate the source parameters for both the active and the subduction regions. The point source seismological model is commonly used when the distance between the source and the strong motion station is greater than the size of the ruptured fault. In this study, the distance between the source and strong motion station is significantly greater for all the events in the active region and the subduction region. Based on the distance between the source and the strong motion station in the northeastern and surrounding region of India, a point source seismological model is used to estimate the source parameters, including path and $Q$ value. For the suitability of the seismological model (Boore, 2003), the estimated fault rupture length $(\mathrm{km})$ and the distance between the source and strong motion station (i.e. the epicentral distance $(\mathrm{km}))$ for the different earthquake events in the northeastern and surrounding region of India are presented in Table 1 for reference. In the seismological model (Boore, 2003), the Fourier amplitude spectrum of ground motion at a site is derived in terms of source and wave propagation functions represented in the general equation (Boore, 2003)

$$
A(f)=(2 \pi f)^{2} C S(f) D(f) P(f) F(f),
$$

where $S(f)$ is the source spectral function, $D(f)$ characterizes the geometrical and anelastic attenuation in the medium, $P(f)$ represents upper crust attenuation and $F(f)$ is the site amplification function. The site amplification function $F(f)$ is taken to be unity at bedrock 
Table 1 Quality factor for the recorded events in the horizontal and vertical components

\begin{tabular}{|c|c|c|c|c|c|c|c|}
\hline \multirow{3}{*}{ Tectonic block } & \multicolumn{3}{|c|}{ Event } & \multirow{3}{*}{$M_{\mathrm{W}}$} & \multirow{3}{*}{ Quality factor $Q(f)$} & \multirow{3}{*}{$\begin{array}{l}\text { Estimated fault } \\
\text { rupture/km }\end{array}$} & \multirow{3}{*}{$\begin{array}{l}\text { Epicentral } \\
\text { distance } / \mathrm{km}\end{array}$} \\
\hline & \multirow{2}{*}{$\begin{array}{c}\text { Date } \\
\text { a-mo-d }\end{array}$} & \multicolumn{2}{|c|}{ Location } & & & & \\
\hline & & Lat. $/{ }^{\circ} \mathrm{N}$ & Long. $/{ }^{\circ} \mathrm{E}$ & & & & \\
\hline \multirow{4}{*}{$\begin{array}{l}\text { Surma } \\
\text { Valley }\end{array}$} & 1988-02-06 & 24.65 & 91.52 & 6.0 & $\begin{array}{l}Q_{\mathrm{LT}}=170.59 f^{0.99}, \sigma_{1} \text { value }(12,0.22) \\
Q_{V}=159.45 f \quad 0.95, \sigma_{1} \text { value }(10,0.33)\end{array}$ & 105 & 169 \\
\hline & 1997-05-08 & 24.89 & 92.25 & 5.9 & $\begin{array}{l}Q_{\mathrm{LT}}=169.55 f^{0.92}, \sigma_{1} \text { value }(10,0.04) \\
Q_{V}=160.25 f^{0.95}, \sigma_{1} \text { value }(11,0.03)\end{array}$ & 95.6 & 97.5 \\
\hline & 2006-08-12 & 24.66 & 92.71 & 5.0 & $\begin{array}{l}Q_{\mathrm{LT}}=160.66 f^{.93}, \sigma_{1} \text { value }(9,0.02) \\
Q_{V}=165.55 f^{0.93}, \sigma_{1} \text { value }(8,0.015)\end{array}$ & 84.53 & 94.65 \\
\hline & 2007-11-11 & 22.15 & 92.39 & 5.5 & $\begin{array}{l}Q_{\mathrm{LT}}=16355 f^{0.92}, \sigma_{1} \text { value }(11,0.025) \\
Q_{V}=167.45 f^{0.94}, \sigma_{1} \text { value }(8.5,0.001)\end{array}$ & 86.65 & 166 \\
\hline $\begin{array}{l}\text { Shillong } \\
\text { Plateau }\end{array}$ & 1986-09-10 & 25.43 & 92.08 & 5.3 & $\begin{array}{l}Q_{\mathrm{LT}}=17145 f^{0.92}, \sigma_{1} \text { value }(11,0.03) \\
Q_{V}=160.05 f^{0.95}, \sigma_{1} \text { value }(9,0.02)\end{array}$ & 78.35 & 81.5 \\
\hline \multirow{4}{*}{$\begin{array}{l}\text { Eastern } \\
\text { Himalaya } \\
\text { region }\end{array}$} & 2006-02-11 & 27.23 & 92.14 & 4.8 & $\begin{array}{l}Q_{\mathrm{LT}}=16965 f^{0.92}, \sigma_{1} \text { value }(10,0.2) \\
Q_{V}=16255 f^{0.94}, \sigma_{1} \text { value }(8,0.01)\end{array}$ & 76.25 & 131 \\
\hline & 2006-02-14 & 27.38 & 88.39 & 5.5 & $\begin{array}{l}Q_{\mathrm{LT}}=16132 f^{0.93}, \sigma_{1} \text { value }(12,0.04) \\
Q_{V}=163 . .45 f^{0.95}, \sigma_{1} \text { value }(10,0.03)\end{array}$ & 87.8 & 329.5 \\
\hline & $2008-10-08$ & 29.76 & 90.33 & 5.5 & $\begin{array}{l}Q_{\mathrm{LT}}=167.45 f^{0.95}, \sigma_{1} \text { value }(11,0.025) \\
Q_{V}=16573 f^{0.93}, \sigma_{1} \text { value }(12,0.026)\end{array}$ & 90.6 & 345 \\
\hline & 2011-09-18 & 27.72 & 88.06 & 6.9 & $\begin{array}{l}Q_{\mathrm{LT}}=18985 f^{0.97}, \sigma_{1} \text { value }(13,0.02) \\
Q_{V}=17355 f^{0.94}, \sigma_{1} \text { value }(12,0.01)\end{array}$ & 110.45 & 235.45 \\
\hline $\begin{array}{l}\text { Assam } \\
\text { Valley }\end{array}$ & 2006-02- & 26.91 & 91.71 & 6.0 & $\begin{array}{l}Q_{\mathrm{LT}}=169.62 f^{0.96}, \sigma_{1} \text { value }(12,0.02) \\
Q_{V}=160.95 f^{0.95}, \sigma_{1} \text { value }(11,0.03)\end{array}$ & 98.65 & 192 \\
\hline \multirow{7}{*}{$\begin{array}{l}\text { Arakan } \\
\text { Yoma } \\
\text { belt region }\end{array}$} & $1987-05-18$ & 25.27 & 94.20 & 5.9 & $\begin{array}{l}Q_{\mathrm{LT}}=178.59 f^{0.97}, \sigma_{1} \text { value }(15,0.04) \\
Q_{V}=169.4 f^{0.95}, \sigma_{1} \text { value }(12,0.03)\end{array}$ & 97.4 & 168.5 \\
\hline & 1988-08-06 & 25.15 & 95.13 & 7.3 & $\begin{array}{l}Q_{\mathrm{LT}}=193.5 f^{0.93}, \sigma_{1} \text { value }(14,0.05) \\
Q_{V}=16825 f^{0.96}, \sigma_{1} \text { value }(13,0.03)\end{array}$ & 169.8 & 268.5 \\
\hline & $1990-01-10$ & 24.75 & 95.24 & 6.4 & $\begin{array}{l}Q_{\mathrm{LT}}=190.45 f^{0.95}, \sigma_{1} \text { value }(15,0.04) \\
Q_{V}=16555 f^{0.93}, \sigma_{1} \text { value }(12,0.03)\end{array}$ & 143.2 & 287.6 \\
\hline & 1995-05-06 & 25.01 & 95.34 & 6.8 & $\begin{array}{l}Q_{\mathrm{LT}}=18845 f^{0.97}, \sigma_{1} \text { value }(15,0.03) \\
Q_{V}=17255 f^{0.91}, \sigma_{1} \text { value }(13,0.04)\end{array}$ & 156.87 & 269.45 \\
\hline & 2007-05-05 & 23.16 & 94.48 & 5.0 & $\begin{array}{l}Q_{\mathrm{LT}}=17662 f^{0.96}, \sigma_{1} \text { value }(12,0.022) \\
Q_{V}=170.34 f^{0.93}, \sigma_{1} \text { value }(11,0.03)\end{array}$ & 87.98 & 197 \\
\hline & 2009-09-03 & 24.33 & 94.67 & 5.9 & $\begin{array}{l}Q_{\mathrm{LT}}=171.45 f^{0.93}, \sigma_{1} \text { value }(11,0.01) \\
Q_{V}=16356 f^{0.92}, \sigma_{1} \text { value }(13,0.02)\end{array}$ & 112.56 & 223 \\
\hline & $2009-12-23$ & 24.36 & 94.81 & 5.6 & $\begin{array}{l}Q_{\mathrm{LT}}=16525 f^{0.95}, \sigma_{1} \text { value }(10,0.013) \\
Q_{V}=16566 f^{0.93}, \sigma_{1} \text { value }(12,0.02)\end{array}$ & 105.6 & 321 \\
\hline
\end{tabular}

level. $C$ is a suitable scaling factor. The widely used source spectral function is the single corner frequency model of Brune (1970) as

$$
S(f)=\frac{M_{0}}{1+\left(\frac{f}{f_{c}}\right)^{2}},
$$

where the corner frequency $\left(f_{\mathrm{c}}\right)$, the seismic moment $\left(M_{0}\right)$ and the stress drop $(\Delta \sigma)$ are related by Boore (2003),

$$
f_{\mathrm{c}}=4.9 \times 10^{6} v_{\mathrm{S}}\left(\frac{\Delta \sigma}{M_{0}}\right)^{\frac{1}{3}}
$$

where $v_{\mathrm{S}}$ is the shear wave velocity in the source region in $\mathrm{km} / \mathrm{s}, f_{\mathrm{c}}$ is in $\mathrm{Hz}$, stress drops $(\Delta \sigma)$ are in bars and seismic moment $\left(M_{0}\right)$ is in dyne-cm. The diminution factor $D(f)$ is defined by Boore (2003) as:

$$
D(f)=G \exp \left[\frac{-\pi f R}{v_{\mathrm{S}} Q(f)}\right],
$$

where $G$ refers to the geometric spreading factor and the second term refers to the anelastic attenuation, accounting for the loss of energy along the wave path. In the above equation $R$ is the hypocentral distance and $Q$ is the quality factor of the region defined by Boore 
(2003):

$$
Q(f)=Q_{0} f^{n}
$$

The parameters $Q_{0}$ and $n$ are determined from past seismic recordings. The high frequency cut filter in the above model is given by Boore (2003) as

$$
P(f)=\exp (-\pi \kappa f),
$$

where the $\kappa$ factor controls the decay of the system.

The scaling factor $C$ is given by Boore (2003) as

$$
C=<R_{\theta \Phi}>\frac{\sqrt{2}}{4 \pi \rho v_{\mathrm{S}}^{3}},
$$

Where $<R_{\theta \Phi}>$ is the radiation coefficient averaged over an appropriate range of azimuth and take-off angle. The coefficient, $\sqrt{2}$, in the above equation is the product of free surface site amplification and partitioning of energy into orthogonal directions. When the motion is considered at the bed rock level, then the amplification function $F(f)$ is unity. The above model has been extensively used to stochastically simulate large samples sizes of ground acceleration time histories (Boore, 2003). This simulated data is useful for establishing empirical relationships that can then be used for engineering applications. This provides an alternative approach for regions with limited strong motion records. The major limitation of this model is that it is one-dimensional and has only a single point source. Nevertheles the above model has been successfully used to simulate strong motion accelerograms in Peninsular India, south of $24^{\circ} \mathrm{N}$ (Iyengar and Raghukanth, 2004). In the absence of sufficient strong motion records in a region, engineers have to take recourse to large-scale simulations of synthetic seismograms, adopting the above seismological model (Iyengar and Raghukanth, 2004; Boore, 2003).

\section{Instrumental database}

The Indian plate is actively subducting under the Eurasian plate, resulting in a subduction zone along the Indo-MyanMar border. northeastern and surrounding region of India can be divided into six tectonic blocks (Goswami and Sharma, 1982). The Arakan Yoma belt

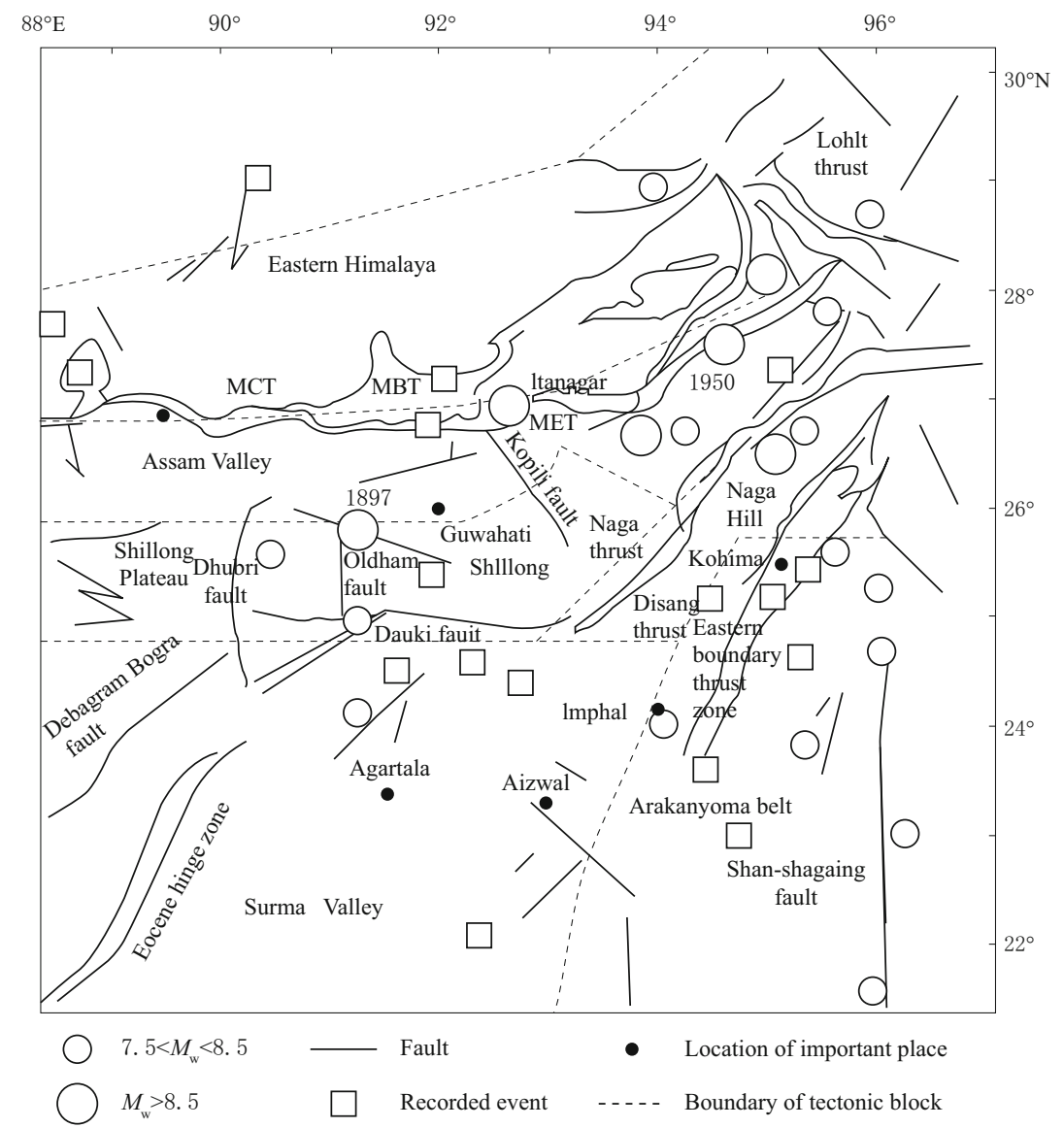

Figure 1 Seismotectonic map (recorded events $M_{\mathrm{W}}>7.5$ ) for the northeastern and its surrounding region of India. 
region is located within the Indo-Burma subduction zone. The Eastern Himalaya, Surma Valley, Shillong Plateau, Assam Valley and Naga Hill region which are not within the subduction zone, correspond to the active region. The six tectonic blocks, along with the 17 recorded event in the northeastern and surrounding region of India are shown in Figure 1. It should be noted that the available data for the 17 past events are not evenly distributed throughout the northeastern and surrounding region of India (Figure 1). Some details about the recorded data are available in the reports from Chandrasekaran and Das (1992, 1993), Sharma (1998). That are, seven events were recorded by the instruments maintained by National Geophysical Research Institute (NGRI) and the Indian Meteorological Department (IMD). In total, there are 546 strong motion accelerograms which are modeled using a point source seismological model (Boore, 2003). This rich database is used here to estimate the three key seismological parameters valid for the northeastern and surrounding region of India. The average distance between the source and the strong motion station for the events in the active tectonic region and the subduction zone vary from $75 \mathrm{~km}$ to $320 \mathrm{~km}$ and $150 \mathrm{~km}$ to $350 \mathrm{~km}$, respectively.

\section{Estimation of the quality factor $(Q)$}

In this study, quality factor $(Q)$ calculations for the earthquake events in the active region and the subduction zone were considered separately. Likewise, the quality factor for the horizontal and vertical components of the 17 recorded events at the various recording stations were calculated separately. Earthquake engineers are mostly concerned with quantified information pertaining to these two components of the ground motion, which are predominantly responsible for most of the earthquake damage to engineering structures. In order to represent the actual hazard for a region, it is essential to study the seismic wave attenuation characteristics from past recorded earthquake activity. The quality factor $(Q)$ is a path parameter. It represents the average attenuation characteristics of the medium. Aki (1980) showed that the $Q$ value is inversely related to the anelastic attenuation of seismic waves, that it varies from place to place and is dependant on the seismotectonic characteristics of the local source region. Knowledge of anelastic attenuation is important because it determines the shape of the high frequency spectrum, whereas the stress drop controls the actual level of the spectrum. Raoof et al. (1999) and Sokolov et al (2002) investigated the anelastic attenuation using the direct regression of the shear wave Fourier amplitude spectra. Motazedian (2006) investigated the anelastic attenuation by carrying out a regression analysis of the Fourier spectra using the earthquake data from Iran. He performed the regression analysis by the maximum likelihood method using the algorithm of Joyner and Boore $(1993,1994)$. The present study, uses the regression analysis of the Fourier amplitude spectra of the available recorded strong motion data to determine the anelastic attenuation characteristics following the point source seismological model.

After substituting all of the terms from the equations (2-7) into the equation (1) and rewriting equation (1), we have

$$
A(f)=\frac{\bar{S}(f)}{\sqrt{R}} \exp \left(-\frac{\pi f R}{v_{\mathrm{S}} Q(f)}\right),
$$

where $\bar{S}(f)=C S(f) P(f) F(f)$

By taking $\log _{10}$ on both sides of the equation (8), we get

$$
\log _{10} A(f)+0.5 \log _{10} R=\log _{10} \bar{S}(f)-\frac{\pi f \log _{10} \mathrm{e}}{v_{\mathrm{S}} Q(f)} R .
$$

This is the equation for a straight line whose intercept is given by the source term $\log _{10} \bar{S}(f)$ and the slope by the $Q$ term. For each earthquake, we plot $\log _{10} A+0.5 \log _{10} R$ versus $R$ and perform a linear regression to determine $Q$ at each frequency. Mitra et al. (2006) successfully calculated the quality factor using the point source seismological model given in equations (1-9).

The frequency-dependent $Q$ term is usually defined as

$$
Q(f)=Q_{0} f^{n}
$$

where $Q_{0}$ is the $Q$ at $f=1.0 \mathrm{~Hz}$ and $n$ gives the frequency dependence of the quality factor $Q(f)$.

Equation (10) can then be rewritten as

$$
\log _{10} Q(f)=\log _{10} Q_{0}+n \log _{10} f .
$$

Similarly, the result is a straight line and a linear regression is carried out over $\log _{10} Q(f)$ versus $\log _{10} f$ to determine the values of $Q_{0}$ and $n$ from the intercept and the slope of the regression line respectively. In this study, two values of the quality factors $Q(f)$ have been calculated. The first is for the horizontal component $\left(Q_{\mathrm{LT}}\right)$, which is calculated by taking the average of the longitudinal and transverse components of the 
recorded strong motion accelerogram. The second quality factor is for the vertical component of the strong motion accelerogram.

\section{Numerical results for the qual- ity factor $(Q)$}

For all available data from the 17 earthquakes in the northeastern and surrounding region of India , initial results are obtained from equations (2-9). For an event that took place on 10 September, $1986, \log _{10} A+$ $0.5 \log _{10} R$ versus $R$ is plotted in Figures $2 \mathrm{a}, 2 \mathrm{~b}$ and $2 \mathrm{c}$ for the horizontal components of the quality factor at the frequencies $0.2 \mathrm{~Hz}, 0.5 \mathrm{~Hz}$ and $5.0 \mathrm{~Hz}$, respectively. Similarly, Figures 2d, 2e and 2f show the results for the vertical components of quality factor at the frequencies $0.5 \mathrm{~Hz}, 5 \mathrm{~Hz}$ and $0.1 \mathrm{~Hz}$, respectively. The slope
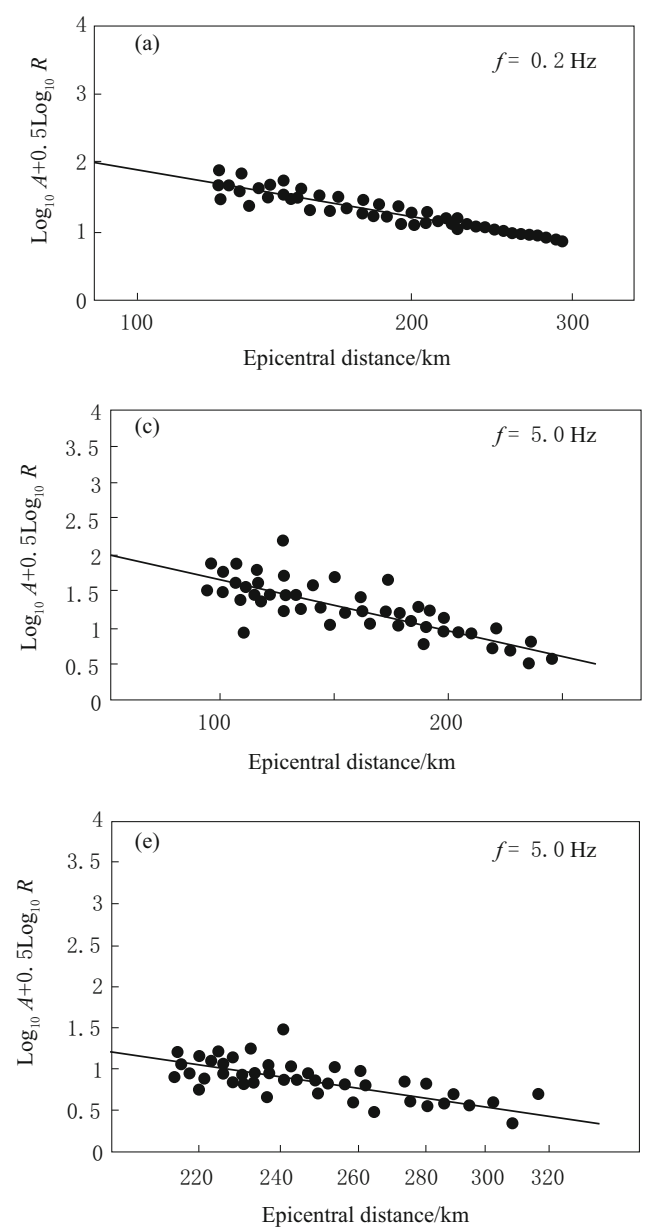

Figure 2 Variation of $\log _{10} A+0.5 \log _{10} R$ versus hypocentral distance (km) for the event of magnitude $\left(M_{\mathrm{W}} 5.3\right)$ on September 10, 1986. Figures 2a-2c are for horizontal component, and Figures 2d-2f are for vertical component. of the straight line that fits the scattered diagram is an estimate of $Q$ at that particular frequency. All such $Q$ values are combined to plot another straight line as per equation (11). For the earthquake on September 10, $1986\left(M_{\mathrm{W}} 5.3\right)$, shown in Figure 2, the dependence of $Q$ on $f$ is given in Figure 3. In this way, all of the events in the database are used to find the respective best fit $Q(f)$. These results are presented in Table 1 along with the standard deviation in $Q_{0}$ and $n$. All of the events are combined with their respective area in the active region and subduction region to get a single $Q(f)$ estimate for the northeastern and surrounding region of India as a whole.

We express the horizontal component of the quality factor as:

$$
Q_{\mathrm{H}}(f)=188.55 f^{0.94}, \quad \sigma_{1} \text { value }(25,0.025)
$$
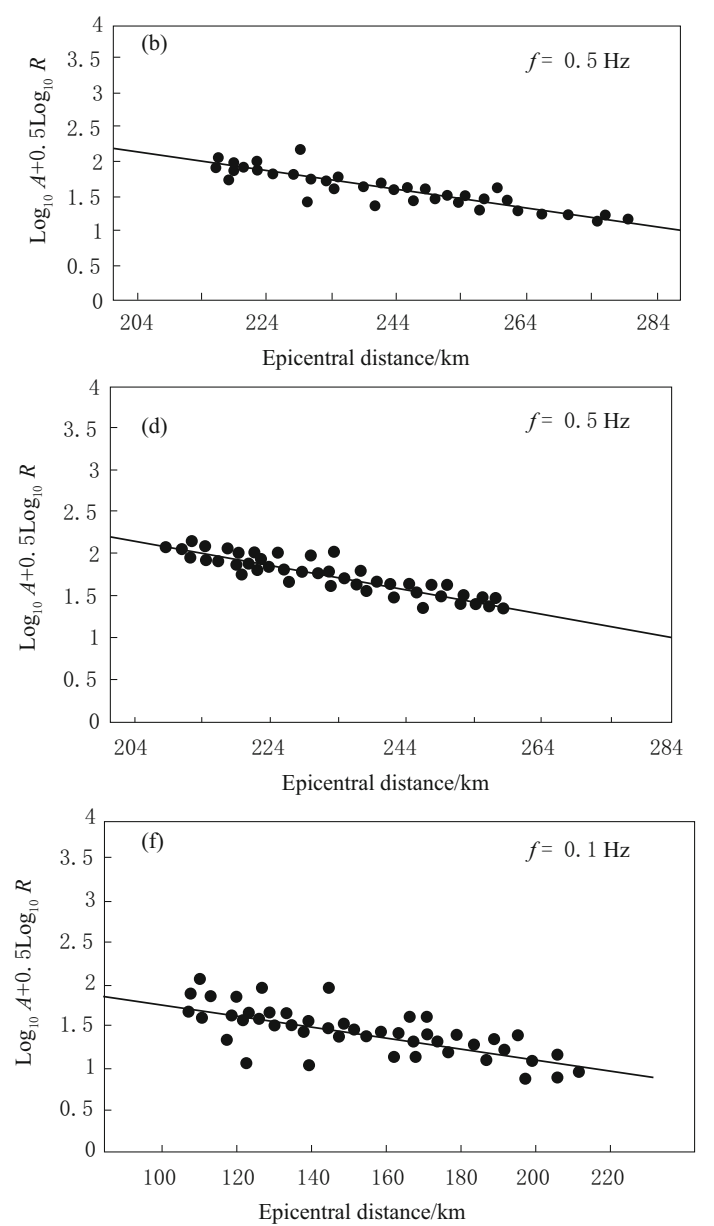
We express the vertical component of the quality factor as:

$$
Q_{\mathrm{V}}(f)=169.76 f^{0.93}, \quad \sigma_{1} \text { value }(20,0.03)
$$

The weighted average of $\log _{10} Q$ versus $\log _{10} f$ of the vertical component of the event on September 10, 1986 is shown in Figure 3. Similarly, the weighted average of $\log _{10} Q$ versus $\log _{10} f$ for the horizontal and vertical components of the earthquake on August 6, 1988 is presented in Figures 4 and 5. These figures illustrate suitable quality factor results with mean value $\pm \sigma_{1}$. The weighted average of $\log _{10} Q$ versus $\log _{10} f$ of the horizontal and vertical components of all the events is presented in Figures 6 and 7. A comparison between the horizontal and vertical components of the quality factor is shown in Figure 8. It can be seen that the horizontal component of the quality factor is greater value than the vertical component.

A comparative study of the quality factors for the six different regions of India some sourrounding regions are represented in Figure 9. The quality factors for the south Indian region and Indian platform are represented by curves 1 and 2, respectively. Curves 3, 4, 5, and 6 represent the quality factor for the Koyna region, the Garwal Himalayas region, the Himalayas region (Gupta and Kumar, 2002) and northeastern and its surrounding region of India, respectively. The quality factors for the south Indian region, Indian platform and the Koyna region, represented by the curves 1, 2 and 3, respectively, are greater than that for the northeastern and its surrounding region of India. The greater quality factor value for the three regions indicates that these regions are more tectonically stable than the northeastern and its surrounding region of India. The quality factor $(Q)$ for the northeastern and its surrounding region of India, represented by curve 6 , is nearly equation those for the Garwal Himalayas region and the Himalayas region, implying that the seismotectonic characteristics of these regions are similar. The quality factor for the Himalayas region (Paul et al., 2003) represented by the curve 5, has a slightly greater avlue with responsive the northeastern and its surrounding region of India for the frequency $0-35 \mathrm{~Hz}$, yet lower value for frequencies greater than $35 \mathrm{~Hz}$. The variation of the quality factor for the northeastern and its surrounding region of India and the Garwal Himalayas region are very small across the entire frequency range. This comparison of quality factor, between different parts of India and some sourrounding regions provides useful information about the similarity in seismogenic characteristics; in addition to stress drop values for different stable and non-stable regions.
Using the past seven earthquake events, Raghukanth and Somala (2009) calculated quality factor of $224 f^{0.93}$ for this region, which was greater than that presented in this study. However, they did not calculate separate quality factor for the active and subduction regions and only used 111 recorded accelerograms.

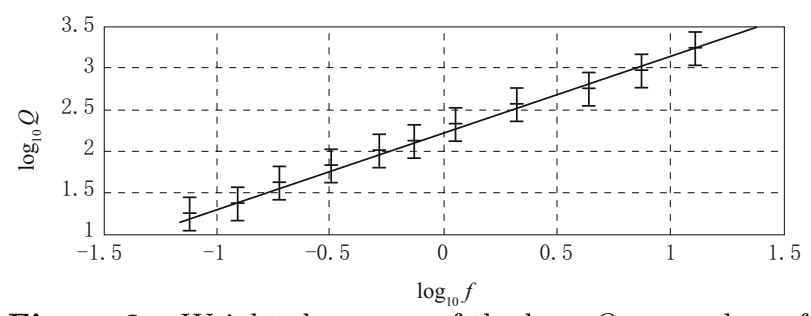

Figure 3 Weighted average of the $\log _{10} Q$ versus $\log _{10} f$ for the vertical component for the earthquake of magnitude $\left(M_{\mathrm{W}} 5.3\right)$ on September 10, 1986.

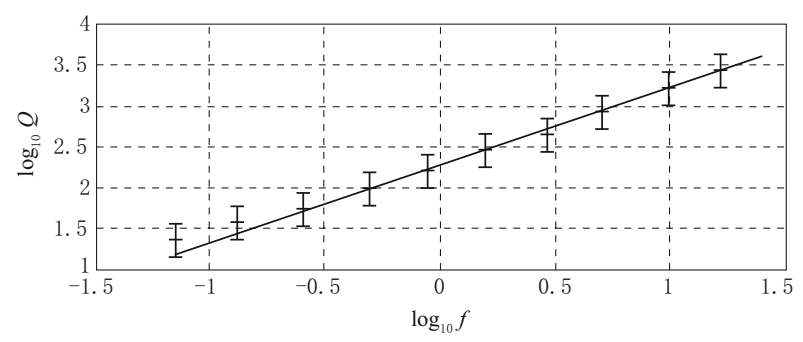

Figure 4 Weighted average of the $\log _{10} Q$ versus $\log _{10} f$ for the horizontal component for the earthquake of magnitude $\left(M_{\mathrm{W}} 7.3\right)$ on August 6, 1988.

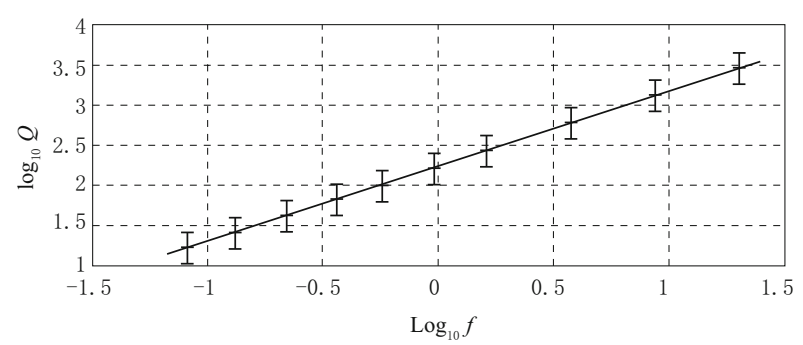

Figure 5 Weighted average of the $\log _{10} Q$ versus $\log _{10} f$ for the vertical component for the earthquake of magnitude $\left(M_{\mathrm{W}} 7.3\right)$ on August 06, 1988.

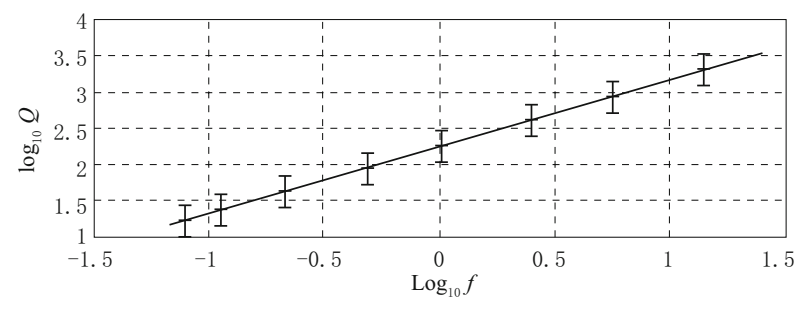

Figure 6 Weighted average of the $\log _{10} Q$ versus $\log _{10}$ (f) for the horizontal component of all the events for the northeastern and surrounding region of India. 


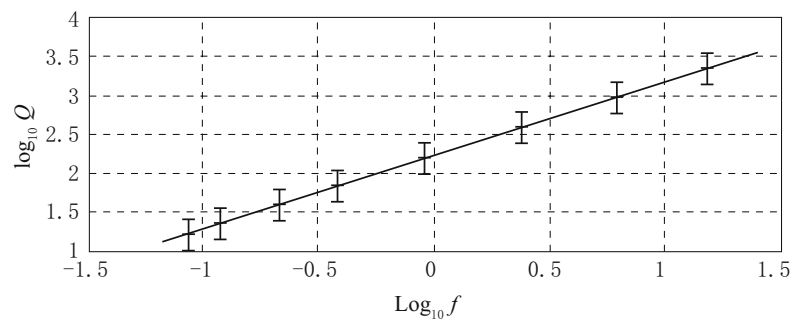

Figure 7 Weighted average of the $\log _{10} Q$ versus $\log _{10} f$ for the vertical component of all the events for the northeastern and surrounding region of India.

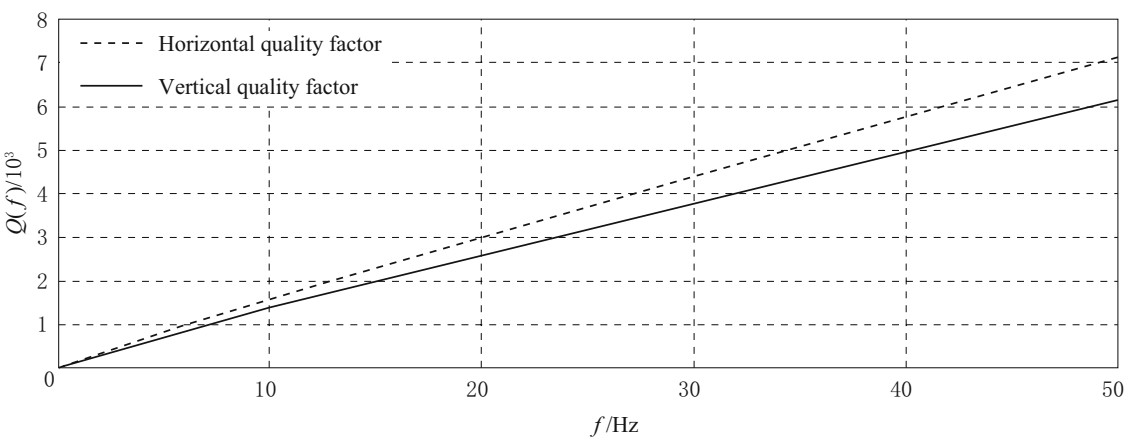

Figure 8 Comparison between Horizontal and vertical Quality factor for all events.

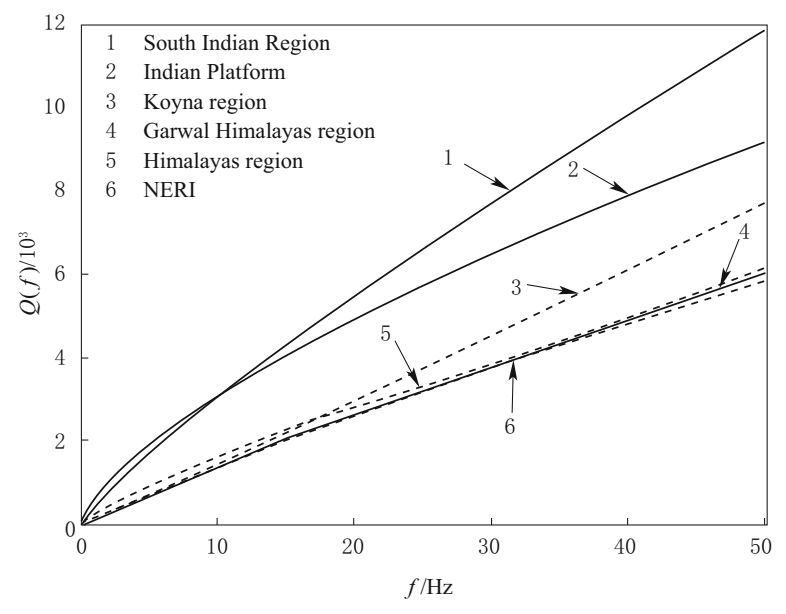

Figure 9 Comparison of the quality factors $Q(f)$ for different parts of India and some sourrounding regions represented by the curves 1 to 6 .

\section{Estimation of the site parameter $(\kappa)$}

The Kappa factor is a very important parameter, which is used for calculating the site effects in attenuation characteristics of seismic waves. One can recognize the type of soil at the recording station based upon the Kappa value. Anderson and Hough (1984) have studied the site parameter of Kappa value, and found that it can be used for reducing the high frequency amplitude by applying it into the expression $\exp (-\pi f \kappa)$. Site amplification $F(f)$ and the attenuation factor $D(f)$ are not considered in calculating the site parameter Kappa factor $(\kappa)$. Kappa factor is used to diminish the spectral amplitude above a certain threshold level and is believed to be primarily a site effect. In this study, the Kappa factor for each recording station from the different events are calculated from the slope of the smoothed log of the Fourier spectral amplitude for frequencies greater than $5.0 \mathrm{~Hz}$. There are 129 recording stations for the available eleven recorded northeastern and its surrounding region of India events. A least squares fit for the Kappa factor to the spectrum for each recording station each record from northeastern and its surrounding region of India has been carried out for the horizontal and vertical components. The Kappa factor calculated for the different recording stations of the horizontal and vertical components (Figures 10 and 11).

The mean values of the Kappa factor for the horizontal and vertical components on a soft bedrock site are $0.06 \pm 0.012$ and $0.05 \pm 0.009$, respectively. The horizontal component of the Kappa factor is found to be greater than the vertical component of the Kappa value $\left(\kappa_{\mathrm{V}}\right)$. The vertical component $\kappa_{\mathrm{V}}$ is less sensitive to the variation of shear wave velocity of near surface deposits. Also, the clear difference between the vertical component $\kappa_{\mathrm{V}}$ and the horizontal component $\kappa_{\mathrm{H}}$ of the Kappa factor suggests that that is dependent on near surface site-specific attenuation effects. The Kappa factor for 
the horizontal and vertical component on the soil site has also been calculated in this study from the recorded data on the soil. The Kappa factor for the horizontal and vertical component on firm soil is 0.08 and 0.07 , respectively. The Kappa factor at bedrock level is 0.006 (Tavakoli and Pezeshk 2005), where shear wave velocity is roughly equal to $3 \mathrm{~km} / \mathrm{s}$ and the Kappa factor for the generic rock is $0.02-0.04$ where shear wave velocity is $0.62 \mathrm{~km} / \mathrm{s}$. Atkinson and Silva (2000) reported the value of kappa factor for the generic rock site is 0.04 , with a corresponding shear wave velocity of $0.62 \mathrm{~km} / \mathrm{s}$. The Kappa factor for the northeastern and its surrounding region of India is 0.0545 and, therefore, the shear wave velocity will be less than $0.62 \mathrm{~km} / \mathrm{s}$. The soil type at the recording stations in northeastern and its surrounding region of India are classified as soft rock and stiff soil based on the calculated site parameter $(\kappa)$ in the study.

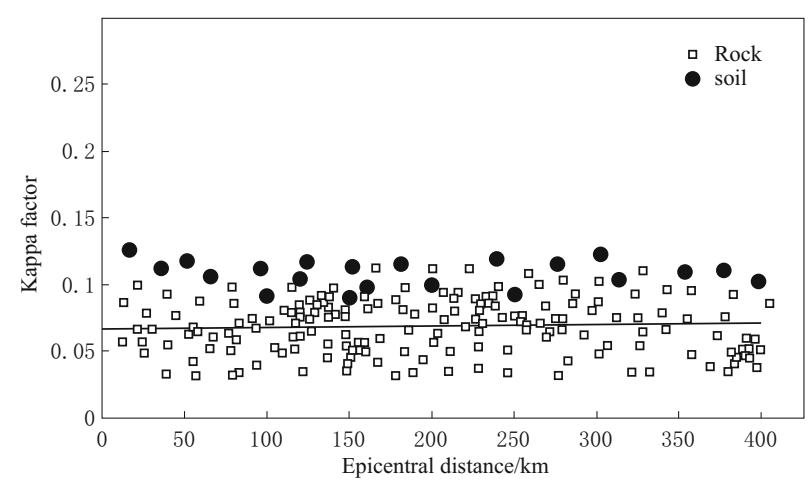

Figure 10 Kappa value for the horizontal components at the recording station.

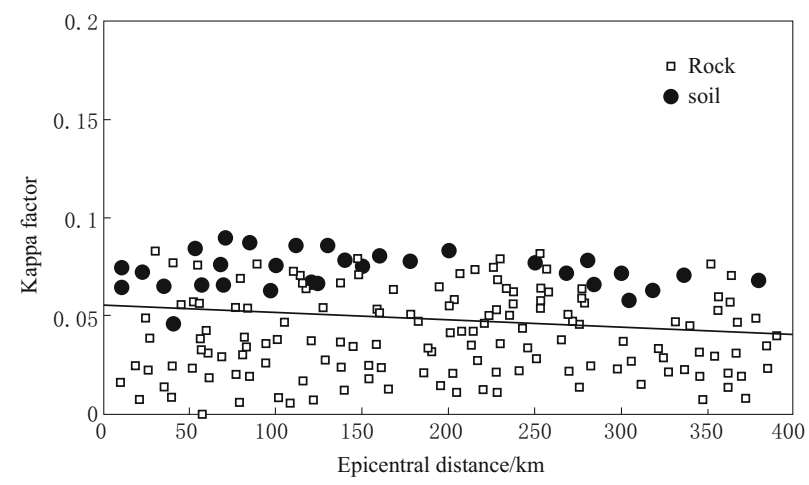

Figure 11 Kappa value for the vertical components at the recording station.

\section{Estimation of stress drop $(\Delta \sigma)$}

If the one-dimensional point source seismological model of Boore $(1983,2003)$ is taken to be valid, the Fourier transform of the acceleration time history at a site can be expressed as in equation (1). For recorded data, this information is readily available. Hence, one can find the stress drop $(\Delta \sigma)$ by substituting equation (3) for corner frequency $f_{\mathrm{c}}$ into $A(f)$ of equation (1) and we can get the following expression

$$
\begin{aligned}
A(f)= & \frac{\sqrt{2}(2 \pi f)^{2} M_{0}}{4 \pi \rho v_{\mathrm{S}}^{3}\left[1+\left\{\frac{f}{4.9 v_{\mathrm{S}} 10^{6}\left(\Delta \sigma / M_{0}\right)^{1 / 3}}\right\}^{2}\right]} G . \\
& \exp \left(-\frac{\pi f R}{v_{\mathrm{S}} Q(f)}\right) \exp (-\pi \kappa f) F(f),
\end{aligned}
$$

where the seismic moment $\left(M_{0}\right)$, which is found as (Hanks and Kanamori, 1979)

$$
\log _{10}\left(M_{0}\right)=1.5 M_{\mathrm{W}}+16.05,
$$

where $M_{\mathrm{W}}$ is the moment magnitude.

The geometric spreading factor ' $G$ ' can be taken as (Knopoff et al. 1973; Nuttli, 1973)

$$
G=\frac{1}{\sqrt{R}}
$$

where $R$ is the hypocentral distance $(\mathrm{km})$.

In this study, recorded events were obtained from the National Geophysical Research Institute (NGRI), Indian Meteorological department (IMD) and IIT Guwahati. These are available for 91 frequencies $(f)$ ranging from 0.0667 to $25 \mathrm{~Hz}$, depending on the type of instrument that was set up for the region. Moreover, in this study, hypocentral distance $R$ in all recorded events is more than $80 \mathrm{~km}$, therefore, the expression for the geometric spreading factor ' $G$ ' as presented in equation (15) is used.

$v_{\mathrm{S}}, \rho$ are the shear wave velocity $(3.6 \mathrm{~km} / \mathrm{s})$ and density $\left(2.8 \mathrm{gm} / \mathrm{cm}^{3}\right)$ at the bedrock level.

In this study, the site amplification function $F(f)$ of the soft rock sites for all available 91 frequencies for each recording station is calculated with respect to bedrock level using the SMSIM Fortran programme (Boore, 2005) using the bedrock level Kappa value $\kappa=0.006$ (Tavakoli and Pezeshk, 2005), shear wave velocity $3.6 \mathrm{~km} / \mathrm{s}$ and the calculated Kappa value $\kappa=0.0545$, quality factor, and the shear wave velocity $v_{\mathrm{S}}=0.62 \mathrm{~km} / \mathrm{s}$ for the northeastern and its surrounding region of India. The nature of the soil at the recording station in northeastern and its surrounding region of India corresponds to soft rock site. In this study, shear wave velocity for the soft rock site located in northeastern and its surrounding region of India is assumed to be $v_{\mathrm{S}}=0.62 \mathrm{~km} / \mathrm{s}$. The site amplification function $F(f)$ of the soft rock site is shown in Figure 12. 


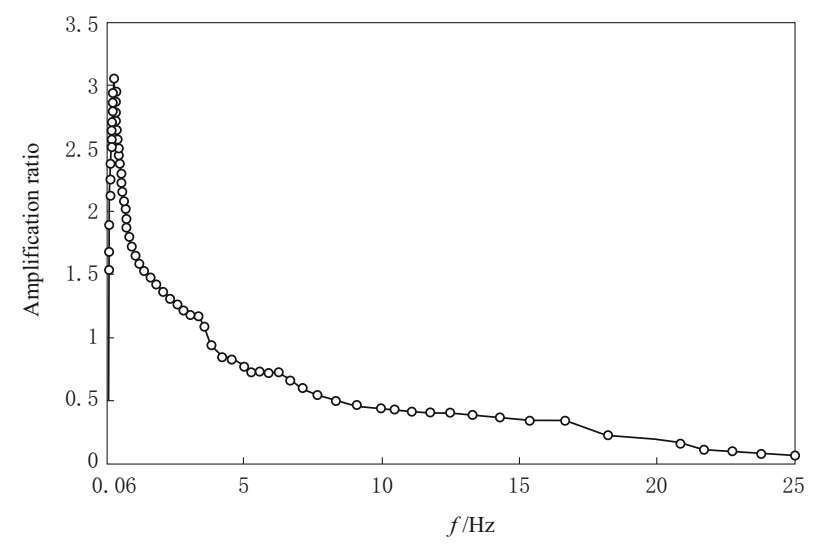

Figure 12 Site amplification function $F(f)$.

Reliable information for stress drop $(\Delta \sigma)$ values is not available for the northeastern and its surrounding region of India. It is assumed that the stress drop $(\Delta \sigma)$ value may varying from 300 to 500 bars for the northeastern and its surrounding region of India and it is assumed as the confidence level of stress drop for all events for northeastern and its surrounding region of India. From equation (14), for given values of epicentral distance $(R)$ and the 91 frequencies for all recording stations for a past event, the theoretical Fourier spectrum $A(f)$ value is calculated for the various stress drop $(\Delta \sigma)$ values ranging from 300 to 500 bars with an increment of 0.05 bars. The frequency content of each theoretically calculated Fourier spectrum $A(f)$ is compared with the actual record of the Fourier spectrum.

To check bias in the calculated stress drop $(\Delta \sigma)$ values, the residuals for all 91 frequencies between 0.0667 and $25 \mathrm{~Hz}$, with respect to epicentral distance $(R)$, are calculated for all records. The distribution of residuals versus hypocentral distance is plotted to rule out a trend of distribution, which is shown in Figure 14. The pattern of the residuals indicates that the calculated stress drop $(\Delta \sigma)$ values are unbiased with respect to hypocentral distance.

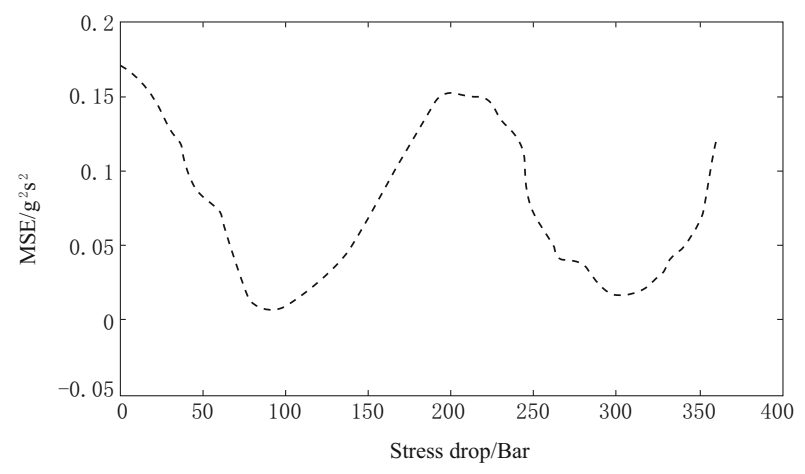

Figure 13 Variation of the MSE with stress drop values for the earthquake on September 10, 1986 and MSE is at its minimum at a stress drop of 80 bars.

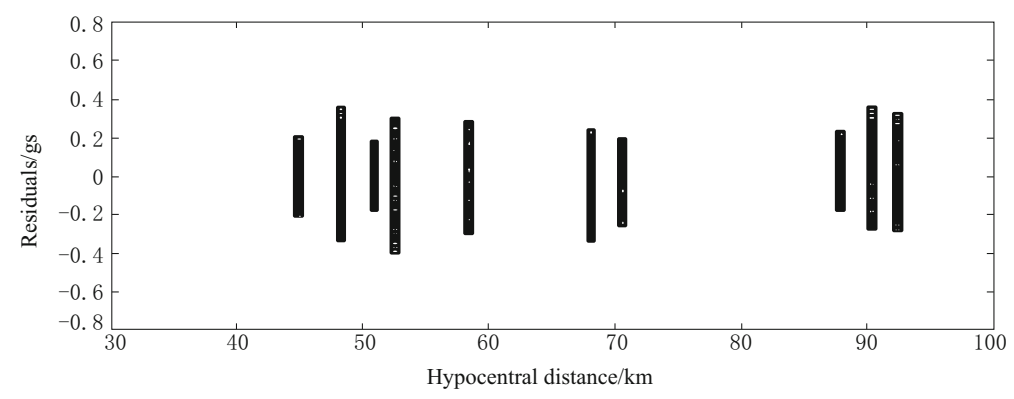

Figure 14 Distribution of residuals for the calculated stress drop for the earthquake on September 10, 1986 for all 91 frequencies.

By taking the average of all frequencies, the mean square error (MSE) is found from the observed Fourier spectra (OFS) and the theoretically calculated Fourier spectra (TCFS) as follows

$$
\mathrm{MSE}=\frac{1}{f(n)} \sum(\mathrm{OFS}-\mathrm{TCFS})^{2}+\sigma_{2},
$$

where $f(n)=91$ is the total number of frequencies for all the recording stations for each past event and $\sigma_{2}$ is the standard deviation values which vary from 0.011 to 0.025. The unit of Fourier spectra (OFS) is gs where ' $\mathrm{g}$ ' is the acceleration due to gravity $\left(\mathrm{m} / \mathrm{s}^{2}\right)$ in SI unit.
Stress drop $(\Delta \sigma)$ can be found by plotting at various recording stations for each past event. Since stress drop $(\Delta \sigma)$ is a source parameter, except for sample variations, it should be the same at all station for a given event.

The mean square error (MSE) between the recorded Fourier spectra and the theoretical Fourier spectra is calculated with respect to various stress drop $(\Delta \sigma)$ values using equation (16). The MSE calculated from the recorded Fourier spectra and theoretical Fourier spectra is plotted with respect to stress drop 
$(\Delta \sigma)$ values ranging from 300 to 500 bars to determine the corresponding stress drop $(\Delta \sigma)$ value, where MSE is at a minimum. The stress drop $(\Delta \sigma)$ corresponding to the global minimum is the desired stress factor for a given past earthquake. Motazedian (2006) has successfully calculated the stress drop $(\Delta \sigma)$ values from recorded events in Iran.

\section{Numerical results of stress drop $(\Delta \sigma)$ for the past events in the active region}

The MSE is defined as the value integrated over all values of $f$ and $R$. In this study, the stress drop $(\Delta \sigma)$ for each of seven earthquake events in the active region has been calculated separately. The MSE for each event with the different stress drop $(\Delta \sigma)$ values have been estimated by plotting MSE versus stress drop $(\Delta \sigma)$ values for all events. The stress drop for an event that gives the minimum value of MSE will be the required stress drop for that event. The variation of the MSE with the stress drop values for the September 10, 1986 earthquake in the Shillong Plateau region is shown in Figure 13. The MSE initially steadily decreases with increasing stress drop values up to 80 bars. With stress drop value greater than 80 bars, the MSE increases up to the stress drop values of 190 bars. Further increases in the stress drop values beyond 190 bars results in the MSE going on to the stress drop value of 300 bars and after this stress drop values, MSE goes on increasing continuously. The MSE is only slightly higher at a stress drop $(\Delta \sigma)$ value of 300 bars than for stress drop $(\Delta \sigma)$ value of 80 bars. Hence, it is clear from Figure 13 that the stress drop value of 80 bars gives the global minimum MSE for the earthquake event on September 10, 1986, in the Shillong plateau region. So, the calculated stress drop $(\Delta \sigma)$ value for this earthquake is 80 bars.

With the estimated stress drop $(\Delta \sigma)$ value determined, the residuals are calculated for the different frequencies and hypocentral distances. These residuals can be plotted to check for bias in its calculated value with respect to the hypocentral distance $(R)$ for the different frequencies. The residuals at all 91 frequencies for the earthquake on September 10, 1986 have been plotted for the stress drop value of 80 bars which is presented in the Figure 14. The residuals are unbiased with respect to the hypocentral distances $(R)$, and, hence, the calculated stress drop $(\Delta \sigma)$ value gives the optimum value for the recorded event on September 10, 1986. The variation of the MSE versus stress drop $(\Delta \sigma)$ values for the earthquake on February 6th, 1988 are presented in Figure 15. The minimum value of the MSE for this event is obtained for the stress drop value of 120 bars. The distribution of the residuals at all 91 frequencies with respect to the hypocentral distance for this event is also presented in Figure 16. The patterns of distributions of residuals are unbiased. The calculated stress drop $(\Delta \sigma)$ values for all individual events for the active region are presented in Table 2 .

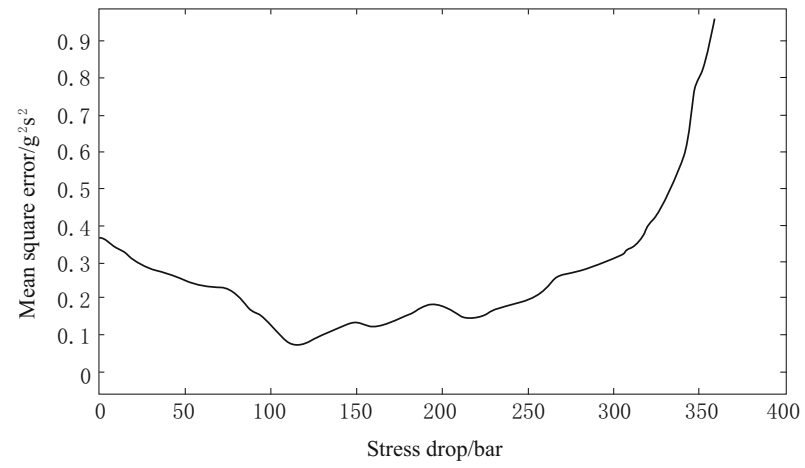

Figure 15 Variation of the MSE with stress drop $(\Delta \sigma)$ value for the earthquake on February 6, 1988 and MSE is at a minimum at a stress drop of 120 bars.

Table 2 Calculated stress drop $(\Delta \sigma)$ values for the active region

\begin{tabular}{|c|c|c|c|c|c|c|}
\hline \multirow{3}{*}{ Tectonic block } & \multicolumn{3}{|c|}{ Event } & \multirow{3}{*}{$M_{\mathrm{W}}$} & \multirow{3}{*}{ Stress drop $(\Delta \sigma)$} & \multirow{3}{*}{ Focal depth $/ \mathrm{km}$} \\
\hline & \multirow{2}{*}{$\begin{array}{c}\text { Date } \\
\text { a-mo-d }\end{array}$} & \multicolumn{2}{|c|}{ Location } & & & \\
\hline & & Lat. $/{ }^{\circ} \mathrm{N}$ & Long. $/{ }^{\circ} \mathrm{E}$ & & & \\
\hline \multirow{4}{*}{ Surma valley } & $1988-02-06$ & 24.65 & 91.52 & 6.0 & 120 & 15 \\
\hline & 1997-05-08 & 24.89 & 92.25 & 5.9 & 148 & 35 \\
\hline & 2006-08-12 & 24.66 & 92.71 & 5.0 & 110 & 25 \\
\hline & 2007-11-17 & 22.15 & 92.08 & 5.5 & 136 & 28 \\
\hline Shillong plateau & 1986-09-10 & 25.43 & 92.08 & 5.3 & 80 & 43 \\
\hline \multirow{3}{*}{ Eastern Himalaya region } & $2006-02-11$ & 27.23 & 92.14 & 4.8 & 86 & 33 \\
\hline & 2006-02-14 & 27.38 & 88.39 & 5.5 & 102 & 21 \\
\hline & 2011-09-18 & 27.72 & 88.06 & 6.9 & 169 & 19 \\
\hline Assam valley & $2006-02-23$ & 26.91 & 91.71 & 5.8 & 165 & 23 \\
\hline
\end{tabular}




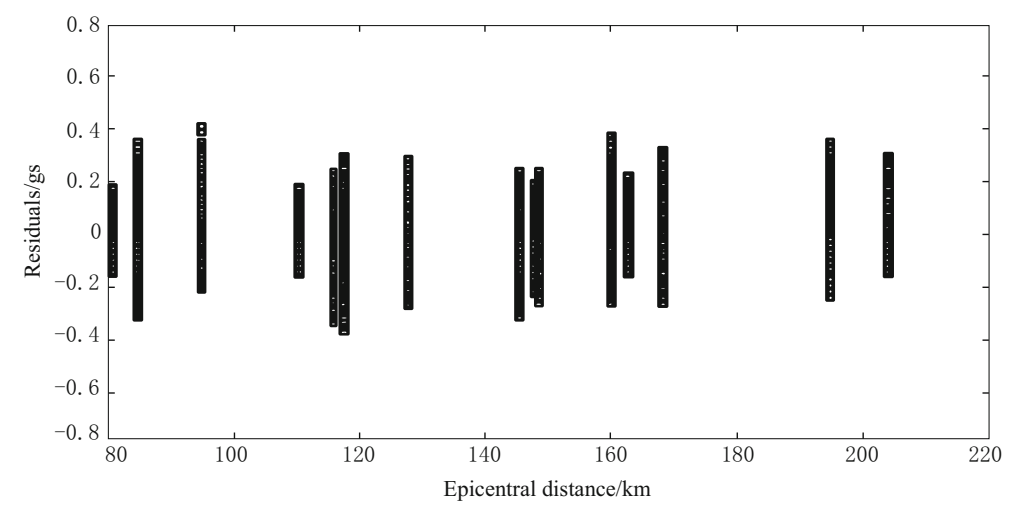

Figure 16 Distribution of residuals for the calculated stress drop $(\Delta \sigma)$ value 120 bar for the earthquake event on February 6, 1988 for all 91 frequencies.

9 Numerical results of stress drop $(\Delta \sigma)$ for the past events in the subduction region (Arakon Yoma belt)

There are four different earthquakes available for the subduction region. The MSE versus stress drops for the earthquake on August 6, 1988 have been plotted in Figure 17. The MSE is a minimum at the stress drop value of 180 bars. For this corresponding stress drop value, the residuals at all 91 frequencies are plotted with respect to the hypocentral distances, shown in
Figure 18. It can be observed from Figure 18 that the residuals are unbiased with respect to the hypocentral distances. The MSE vs. stress drops for the earthquake on January 10, 1990 is plotted in Figure 19 and it can clearly be seen that the MSE is at its minimum for the corresponding stress drop value of 165 bars. Presented in Figure 20 residuals are plotted at all 91 frequencies with respect to the hypocentral distances for this event. It can be seen in Figure 20 that the residuals are unbiased with respect to the hypocentral distances. The calculated stress drop $(\Delta \sigma)$ values for all the individual events for the subduction region are presented in the Table 3 .

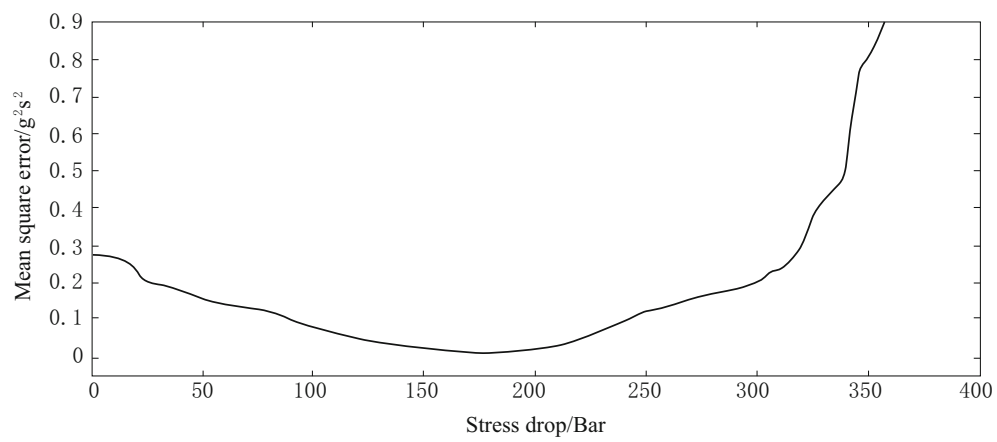

Figure 17 Variation of the MSE with stress drop $(\Delta \sigma)$ values for the earthquake on August 6,1988 and MSE is at a minimum at the stress drop value of 180 bars.

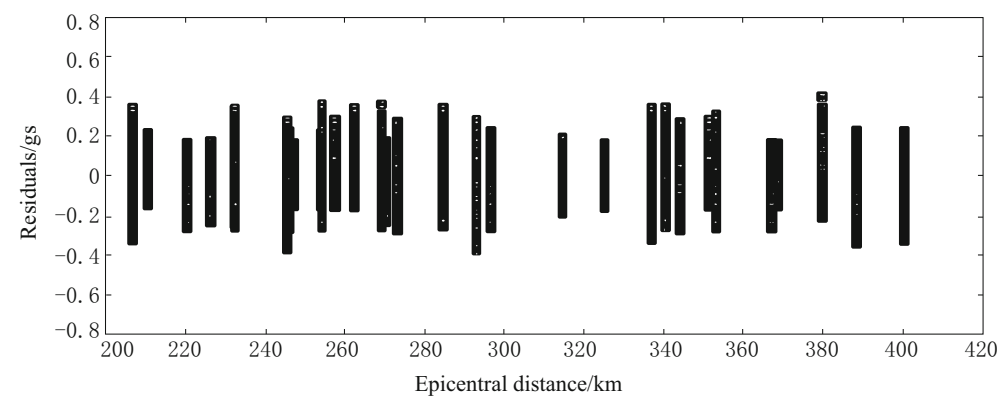

Figure 18 Distribution of the residuals for the calculated stress drop value of 180 bars for the earthquake event on August 6, 1988 for all 91 frequencies. 


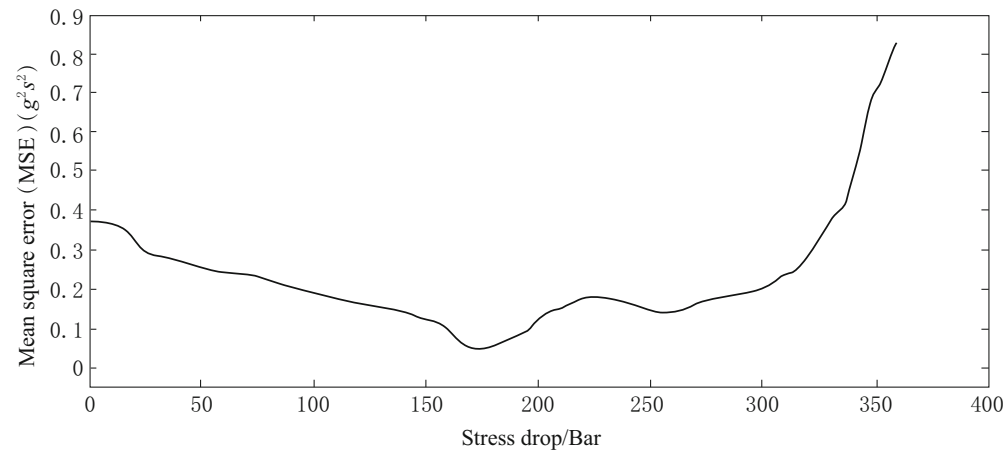

Figure 19 Variation of the MSE versus stress drop $(\Delta \sigma)$ values for the earthquake on January 10,1990 and MSE is at a minimum at the stress drop value of 165 bars.

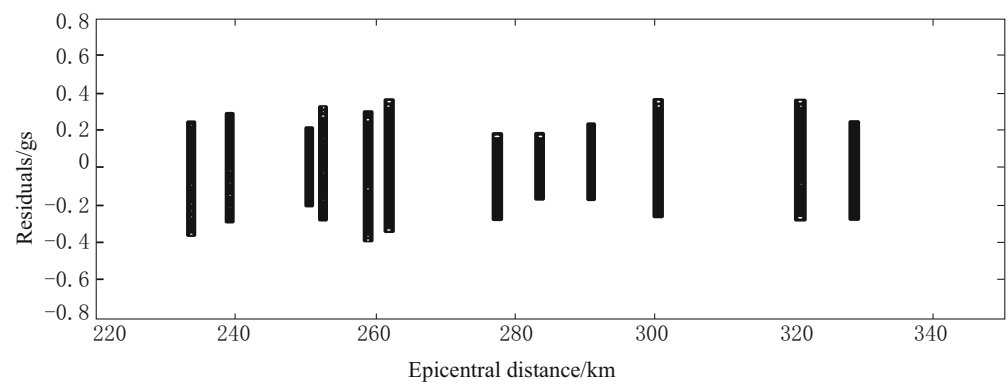

Figure 20 Distribution of the residuals for the calculated stress drop $(\Delta \sigma)$ value 165 bars for the earthquake event on January 10, 1990 for all 91 frequencies.

Table 3 Calculated stress drop $(\Delta \sigma)$ values for the subduction region

\begin{tabular}{|c|c|c|c|c|c|c|}
\hline \multirow{3}{*}{ Tectonic block } & \multicolumn{3}{|c|}{ Event } & \multirow{3}{*}{$M_{\mathrm{W}}$} & \multirow{3}{*}{ Stress drop $(\Delta \sigma)$} & \multirow{3}{*}{ Focal depth $/ \mathrm{km}$} \\
\hline & \multirow{2}{*}{$\begin{array}{c}\text { Date } \\
\text { a-mo-d }\end{array}$} & \multicolumn{2}{|c|}{ Location } & & & \\
\hline & & Lat. $/{ }^{\circ} \mathrm{N}$ & Long. $/{ }^{\circ} \mathrm{E}$ & & & \\
\hline \multirow{8}{*}{ Arakan Yoma belt region } & $1987-05-18$ & 25.27 & 94.20 & 5.9 & 155 & 50 \\
\hline & 1988-08-06 & 25.15 & 95.13 & 7.3 & 180 & 91 \\
\hline & 1990-01-10 & 24.75 & 95.24 & 6.4 & 165 & 119 \\
\hline & 1995-05-06 & 25.01 & 95.34 & 6.8 & 176 & 122 \\
\hline & 2007-05-05 & 23.16 & 94.48 & 5.0 & 124 & 93 \\
\hline & $2008-10-08$ & 29.76 & 90.33 & 5.5 & 145 & 09 \\
\hline & 2009-09-03 & 24.33 & 94.67 & 5.9 & 167 & 95 \\
\hline & 2009-12-09 & 24.36 & 94.81 & 5.6 & 171 & 124 \\
\hline
\end{tabular}

\section{Comparison of the stress drop} $(\Delta \sigma)$ values in the two parts in northeastern and its surrounding region of India

The calculated stress drops $(\Delta \sigma)$ for the subduction region earthquakes are greater than that of the active region. It is clear from Table 1 that the stress drop $(\Delta \sigma)$ values for the active region earthquake events vary from 80 to 165 bars. The stress drop $(\Delta \sigma)$ values for the subduction region earthquakes vary from 155 to 180 bars, which are presented in Table 2. By combining the results of the stress drop $(\Delta \sigma)$ values in the active region and subduction region, we can conclude that stress drop values for the northeastern and its surrounding region of India vary from 80 to 180 bars. Fixing of the stress drop $(\Delta \sigma)$ values in the present study depends on the recorded event for the magnitudes $M_{\mathrm{W}} 4.8-7.3$ and these values may be different for events with magnitudes greater than 7.5. The theoretical calculated Fourier amplitude spectrum with the calculated stress drop $\Delta \sigma$ values are compared with the recorded spectrum for the earthquake of magnitude $M_{\mathrm{W}} 7.3$ on August 6th, 1988, and are shown in Figure 21. The observed Fourier am- 
plitude spectrum represented by the solid line for magnitude 7.3 gives an average value with the theoretically calculated Fourier amplitude spectrum represented by the thick line that is connected with a circle to the stress drops $\Delta \sigma=180$ bar. Similar comparison of the observed Fourier amplitude spectra with the recorded Fourier amplitude spectra for all the recorded events has been carried out in the present study for the calculated stress drop $(\Delta \sigma)$ values and several are shown in the Figures 21 and 23. The theoretical calculated Fourier amplitude spectra with the calculated stress drop values compare well with the observed Fourier amplitude spectrum and the best fit between the model and observed spectrum justifying the applied method in the present study.

Raghukanth et al. (2009) also calculated the stress drop values for the same region from 111 threecomponent records coming from seven earthquakes with magnitudes ranging from $M_{\mathrm{W}} 5.2$ to 7.2 . The obtained stress drops of the seven events lie between 128 and 282 bar. In the present study, stress drop values are obtained from the 546 three-component records from 17 earthquake events, considering the individual event in the active and subduction regions separately. Stress drop $(\Delta \sigma)$ values for the subduction region vary from 124 to 180 bars and for the active region vary from 80 to 169 bars.

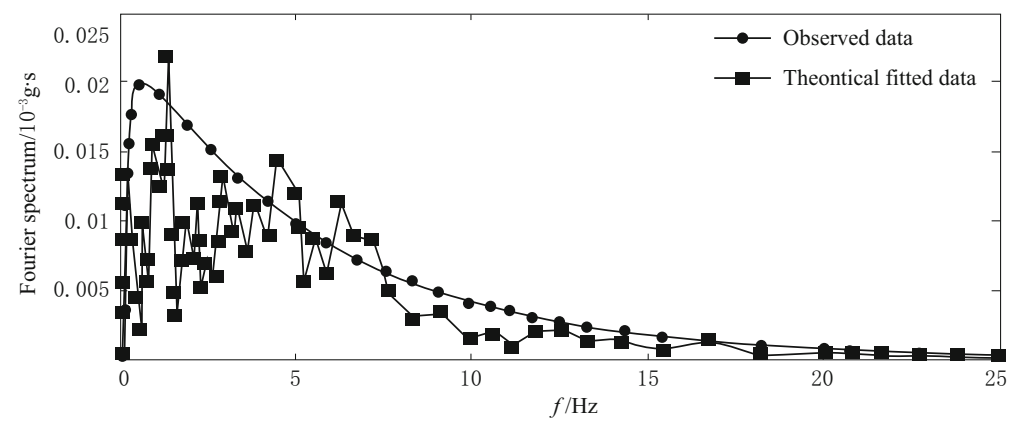

Figure 21 Fourier spectra for the observed data and theoretical data for the earthquake of magnitude $M_{\mathrm{W}} 7.3$ at the station Dauki on August 6, 1988 for stress drop $(\Delta \sigma)$ value of 180 bars in the Arakan Yoma belt region.

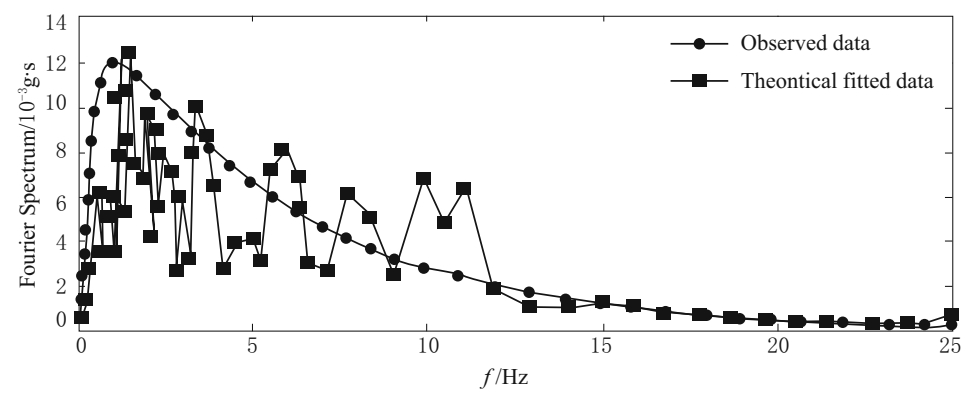

Figure 22 Fourier spectra for the observed and theoretical data for the earthquake of magnitude $M_{\mathrm{W}} 6.0$ at station Shillong on February 6, 1988 for a stress drop $(\Delta \sigma)$ value of 120 bars in the active region.

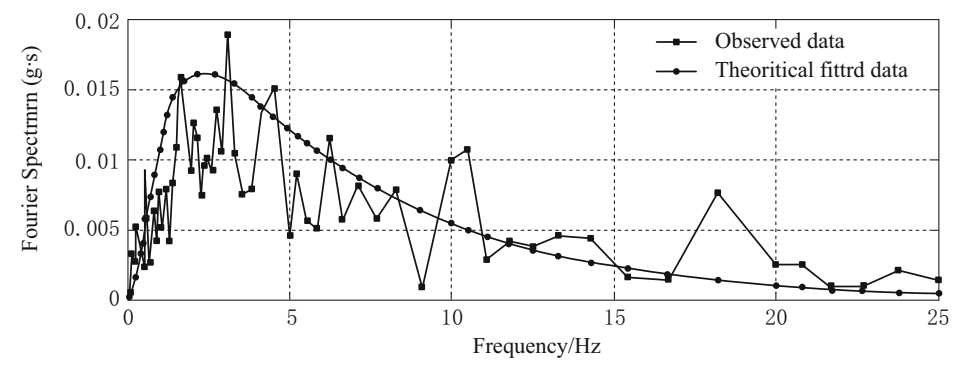

Figure 23 Fourier spectra for the observed and theoretical data for the earthquake of magnitude $M_{\mathrm{W}} 5.3$ at the station Nongpoh on September 10, 1986 for the stress drop $(\Delta \sigma)$ value of 80 bars in the active region. 


\section{Summary and discussion}

In this study, three seismological parameters have been calculated from 17 recorded events using a point source seismological model. Due to the greater quality factor value for all frequencies, the northeastern and its surrounding region of India is interpreted to be more tectonically unstable than the southern India, the Indian platform and the Koyna region. The stress drop values in the northeastern and its surrounding region of India are limited to 180 bars, and this lower value of stress drops indicates an unstable region. The stress drop values for the tectonically stable region are generally greater and are in the range of 300 bars. These seismological model parameters are presented for the first time for the northeastern and its surrounding region of India. These parameters will be useful in framing the ground motion attenuation relation and an engineering hazard estimation methodology for the northeastern and its surrounding region of India. The point source model of Boore (2003) in the frequency domain has been selected in this study. This is a versatile model capable of reflecting region specific source, path, and site characteristics. This model also incorporates other uncertainties (radiation pattern, focal depth, etc.) in simulation of strong ground motion. The large database consisting of 546 records from seventeen earthquakes has lead to interesting results on the above three parameters.

The northeastern and its surrounding region of India is composed of active and subduction regions. The characteristics of both regions are different in terms of stress drop and quality factor. Attenuation relation can be derived by the stochastic simulation of the ground motion accelerogram by calibrating the region specific seismological parameters for a region having sparsely recorded events. The accuracy of the attenuation relation depends on the simulated samples of the ground motion parameters in the stochastic process. Earthquake model parameters such as the quality factors, site parameter, and stress drop values are the important key parameters used in the stochastic simulation of the ground motion. The quality factor in the active region is lower than that of the subduction region. The stress drop values for the subduction region are higher than the active region.

Several authors have discussed the nature of the soil of the recording station for this region, but the actual nature of the soil of the recording stations located in northeastern and its surrounding region of India is not available. Sharma (1998) described the nature of the recording station for this region as soil and rock. Sandip and Gupta (2006) also described the nature of soil of the recording station for the northeastern and its surrounding region of India as soft rock and firm ground soil. Therefore, it is not known to what confidence level the nature of soil or rock of the recording station for this region is fixed as soft rock or firm ground soil. The Kappa factors for all the recording stations have been calculated separately in the present study. On the basis of this calculated Kappa value in this study, the nature of the soil type of the recording station can be assumed as $\mathrm{C}$ type rock/stiff soil as per the classification specified in NEHRP (2001) based on the average top $30 \mathrm{~m}$ shear wave velocity. The Kappa factors calculated from the recorded strong motion accelerogram provide useful information about the nature of soil of the recording station.

\section{Conclusions}

The results of this study are helpful in calibrating the proposed seismological model of equation (1) to the northeastern and its surrounding region of India. Thus the model would be region-specific and will be able to reflect the particular seismological properties of the northeastern and its surrounding region of India. The stress drop, quality factor, and Kappa values have been calculated based on the recorded Fourier spectra of the northeastern and its surrounding region of India. These model parameters are important in stochastic simulation of ground motion for deriving the attenuation relationship for the northeastern and its surrounding region of India which can be further used in probabilistic seismic hazard analysis. These parameters also give the impression of low frequency numerical wave propagation simulation using the finite differences or spectral methods.

Acknowledgements The author is extremely thankful to Profs. Iyengar R N and Raghukanth S T G for their valuable suggestions and kind cooperation for this work.

\section{References}

Anderson J and Hough S (1984). A model for the shape of the Fourieramplitude spectrum of acceleration at high frequencies. Bull Seismol Soc Am 74: 1 969-1 993.

Atkinson G M and Boore D M (1998). Evaluation of models for earthquakesource spectra in eastern North America. Bull Seismol Soc Am 88: 917-934. 
Atkinson G M and Silva W (2000). Stochastic modeling of California Groundmotions. Bull Seismol Soc Am 90: 255-274.

Beresnev I A and Atkinson G M (2002). Source parameters of earthquakes ineastern and western North America based on finite-fault modeling. Bull Seismol Soc Am 92: $695-710$.

Boore D M (1983). Stochastic simulation of high frequency ground motionbased on Seismological models of the radiated spectra. Bull Seismol Soc Am 73: 1 865-1 894.

Boore D M (2003). Simulation of ground motion using the stochastic method.Pure Appl Geophys 160: 635-676.

Boore D M (2005). SMSIM Fortran program for simulating ground motions fromearthquakes: Version 2.3. US Geo Surv Open file report 96-80-A.

Brune J (1970) Tectonic stress and the spectra of seismic shear waves fromearthquakes. J Geophys Res 75: 4 9975009.

Chandrasekaran A R and Das J D (1992). Strong motion arrays in India andanalysis of data from Shillong array. Current Science 62: 233-250.

Chandrasekaran A R and Das J D (1993). Strong earthquake ground motion datain EQINFOS for India: Part 1B. In: Trifunc M D, Todorovski M I and Lee V W edits. Report No. CE 9304, Roorkee, India and Los Angeles, California, pp.190

Goswami H C and Sharma S K (1982). Probabilistic earthquake expectancy inthe Northeast Indian region. Bull Seismol Soc Am 72: 999-1 009.

Hanks T C and McGuire R K (1981). The character of high frequency strongground motion. Bull Seismol Soc Am 71: 2 071-2 095.

Hanks T C and Kanamori H (1979). A moment-magnitude scale. J Geophys Res 84: 2 348-2 350.

Iyengar and Raghukanth (2004). Attenuation of strong ground motion inPeninsular India. Seism Res Lett 75: $530-541$.

Joyner W B and Boore D M (1993). Method for regression analysis of strongmotion data. Bull Seismol Soc Am 83:
469-487.

Joyner W B and Boore D M (1994). Errata on Joyner and Boore (1993). Bull Seismol Soc Am 84: 955-956.

Knopoff L, Schwab F and Kausel E (1973). Interpretation of Lg. Geophys J Res Astr Soc 33: 389-404.

Mitra S, Priestly K, Gaur V K and Rai S S (2006). Frequency dependent Lgattenuation in the Indian Platform. Bull Seismol Soc Am 96(6): 2 449-2 456.

Motazedian D (2006). Region specific key seismic parameters for earthquakesin Northern Iran. Bull Seismol Soc Am 96(4A): 1 383-1 395.

Nuttli O W (1973). Seismic wave attenuation and magnitude relation foreastern North America. J Geophys Res 78: 876-885.

Raghukanth S T G and Somala S N (2009). Modeling of strong-motiondata in northeastern India: $Q$, stress drop, and site amplification. Bull Seismol Soc Am 99(2A): 705-725, doi: 10.1785/0120080025.

Raoof M, Hermann R and Malagnini L (1999). Attenuation and excitation ofthree components ground motion in Southern California. Bull Seismol Soc Am 89: 888902.

Sharma M L (1998). Attenuation relationship for estimation of peak groundhorizontal acceleration using data from strong-motion arrays in India. Bull Seismol Soc Am 88:1 063-1 069 .

Sokolov V Y, Loh C H and Wen K L (2002). Comparision of the Taiwan Chi-Chiearthquake strong motion data and ground motion assessment based on spectralmodel from smaller earthquakes in Taiwan. Bull Seismol Soc Am 92: $1855-1877$.

Tavakoli B and Pezeshk S (2005). Empirical stochastic ground motionprediction for Eastern North America. Bull Seismol Soc Am 95(6): 2 283-2 296.

Toro G R, Abrahamson N A and Schneider J F (1997). Model of strong groundmotions from earthquakes in central and eastern North America: Bestestimated and uncertainties. Seism Res Lett 68: 41-57. 